\title{
Corpo, morte e território: etnografia com os Guarani e Kaiowa
}

Resenha: MORAIS, Bruno Martins. Do corpo ao pó: crônicas da territorialidade kaiowá e guarani nas adjacências da morte. São Paulo, Editora Elefante, 2017.

Caetano Tola ${ }^{1}$

Uma foto em preto e branco mostra uma cerca de arame farpado rompida separando o fotógrafo de um jovem. De cocar, rosto pintado e arco e flecha na mão este jovem olha para trás e como que interrompendo sua caminhada encara o leitor. Ao seu lado uma criança realiza o mesmo movimento, vira o pescoço e olha para uma outra direção. Eles caminham para um cenário de descampado, o mato baixo é ocupado apenas por essas duas pessoas e centenas de cupinzeiros.

Essa é a imagem que abre o livro "Do corpo ao pó: crônicas da territorialidade Guarani e Kaiowá nas adjacências da morte" escrito por Bruno Martins Morais como conclusão de seu mestrado no PPGAS-USP, premiado como melhor dissertação de mestrado em Ciências Sociais pela ANPOCS em 2016 e publicado pela Editora Elefante em 2017. A esta imagem se seguirão imediatamente mais quatro: três pessoas cruzam uma cerca em direção a um descampado, estão agachadas passando por entre os fios de arame de costas para quem lê; no descampado três pessoas encaram o leitor, uma ao fundo de pé, outra já no primeiro plano apoiada em um cupinzeiro ao lado de uma outra, também em primeiro plano, deitada de bruços no mato baixo; numa cerca, tanto do lado de "dentro" 
quanto no de "fora" um grupo de cinco pessoas se apoiam observando atentamente algo fora de campo; em primeiro plano um homem empunha um arco e flecha apontando para algo fora de campo, uma dezena de pessoas aparecem desfocadas ao fundo; numa estrada de terra, um grupo de cinco pessoas segue sobre motos em direção ao fotógrafo. Em primeiro plano um homem de boné e rosto pintado encara o leitor. Por fim, um plano fechado no rosto de um homem com cocar de penas e arco nas costas que, sobre uma moto, encara o fotógrafo. Um pano cobre boa parte do rosto do retratado deixando apenas os olhos à mostra.

Não há qualquer tipo de legendas para essas imagens encadeadas em sequência que em folhas pretas precedem o próprio título do livro. Elas dão o tom do que será elaborado, uma reflexão sobre os sentidos que Guarani e Kaiowá atribuem a corpo, morte e território diante do cerco imposto pelo agronegócio no estado do Mato Grosso do Sul. Nesse anúncio do que está por vir, nessa pequena narrativa imagética, Morais também mostra o caminho com que construiu seu trabalho, atravessa a cerca junto com seus interlocutores e desafia a si mesmo a compreender como os acampamentos e as retomadas conformam uma rede de relações a organizar a cosmologia Guarani e Kaiowá numa situação de extermínio.

O trabalho é construído a partir de dois eixos, nos 2 primeiros capítulos fala especificamente da terra tratando do histórico da colonização e estrutura agrária do Mato Grosso do Sul bem como das estratégias de subversão dos indígenas ao espaço imposto pelo estado nacional. Nesse eixo aparece com destaque o termo jopara (mistura) relacionado ao cerco dando conta de uma dinâmica onde as "boas" distâncias não podem mais ser praticadas desorganizando os sentidos da vida social dos indígenas. O segundo eixo, que aparece nos dois capítulos finais, trata dos sentidos do território, de como o atravessamento de relações entre terra e corpo constrói a noção de pessoa. Se destacam nesse momento as descrições nativas de angué, uma parte constituinte do corpo Guarani e Kaiowá que após a morte irá organizar uma série de relações da vida da comunidade.

Apoiado nesses eixos, Morais se depara com a questão de se as categorias nativas encontradas no campo seriam elaborações "próprias" de um ideário Guarani e Kaiowá ou efeitos da dinâmica do cerco. Para essa questão o autor oferece algumas imagens como a do caleidoscópio ou a do pêndulo para demonstrar que a concepção de territorialidade construída pelos indígenas transita por esses dois polos, assim existindo de forma 
complementar. As cercas estão sendo cruzadas, atravessadas, ressignificadas constantemente e é a descrever e compreender esse movimento que o trabalho se dedica.

Senhor Arnaldo aponta no próprio corpo as escoriações sofridas pelo seu filho ao morrer após ter sido arremessado, ou ter caído, não se sabe, de uma caminhonete. O corpo é o local de se descrever a morte, é por ele também que o território Guarani e Kaiowá vai se encher de sentido. Articulando dados do CIMI o trabalho nos mostra que o Mato Grosso do Sul concentra, na média de 2003 a 2013, 55\% dos assassinatos de indígenas no Brasil. Além disso a taxa de suicídio de indígenas no estado é 13 vezes maior do que a média nacional e 7 vezes maior do que o dado de referência da ONU para uma epidemia. Nesse contexto, Morais coloca que "não há morte de indígena que não esteja em disputa, nem uma motivação suficientemente clara" (MORAIS, 2017:61).

Ao fazer o histórico da estrutura fundiária sulmatogrossense da ocupação pelo mate, passando pela colonização da "marcha para o oeste" aos grandes latifúndios de cana da atualidade, Morais mostra o processo de disciplinarização do corpo Guarani e Kaiowá para o trabalho, em paralelo ao seu confinamento nos espaços delimitados pelas reservas. Tendo a vida restringida a esse pequeno espaço das reservas a categoria nativa jopara, a mistura, reflete sobre os efeitos do confinamento que produz uma desorganização cosmológica. Nada fica no lugar certo, roças, cemitérios e casas não respeitam a distância ideal: vivos e mortos se misturam, parentes e não aparentes vivem juntos. A dispersão é interrompida impedindo a própria reprodução da vida social. Essa desorganização espacial é também a desorganização do corpo, no caso o seu "esvaziamento". Morais descreve a cena de uma mãe que ao enterrar seu filho afirmou que o caixão estava vazio. Nesse mesmo sentido, uma professora afirma a vida na reserva repleta de corpos vazios, inacabados e que a escola formal não cumpriria o papel de preenchê-los pois se dedica só a impor um conteúdo e não a orientar o movimento. O corpo vazio não caminha, ele perambula. Os jovens com os corpos esvaziados, desorientados, praticam atos violentos em gangues assustando a vida dentro da reserva. Essa imagem do corpo vazio perambulando é oposta à do corpo saudável que caminha orientado. Nesse sentido, os acampamentos de retomada aparecem como processo de reterritorialização de resistência. Para além de uma dinâmica administrativa, de uma reivindicação fundiária frente ao estado, tais acampamentos se fundamentam na reprodução de um modo de vida específico pautado na circulação de pessoas, objetos, afetos, parentes, pessoas, vivos e mortos. Se nas reservas a jopara se impõe os acampamentos 
vêm reorganizar o espaço e orientar o movimento; se as reservas são os muros de contenção erguidos pelo projeto nacional a bloquear o espalhamento de Guaranis e Kaiowás pelas terras do Mato Grosso do Sul, os acampamentos são o atravessamento desse muro a reivindicar uma nova forma de assentamento pautada em um processo coletivo de autodeterminação. Como coloca Morais:

A vista dessas ocupações precárias, às vezes nos fundos de pasto, nos cantos de plantações, às vezes entre a cerca e a estrada na faixa de segurança das rodovias, são uma lembrança constante à sociedade, ao Estado, aos proprietários de terra, das contradições inerentes a processo de colonização que estabeleceu a estrutura fundiária do Mato Grosso do Sul (MORAIS, 2017:136)

A estes que rompem o muro e passam a se instalar nas bordas, nos fundos, nos cantos a morte acontece por tiro, por atropelamento, por envenenamento a partir do despejo de agrotóxicos, enfim, uma série de eventos violentos gerados por um modelo de gestão de conflito construído a partir da profissionalização e terceirização da violência por meio de empresas de "segurança privada" e assentado num imaginário de que "lugar de índio é na Reserva". Morais acompanha de perto um desses acampamento, o Apyka'i, que desde 2002 vem transitando entre a beira da estrada e os cantos de uma fazenda com o propósito de retomar a área para os indígenas.

Em seu trabalho de campo, o autor observa como Damiana, cacique do acampamento, transita da esfera política do Estado na pauta de reivindicação do território para o emaranhado que compõem a rede de relações dentro e fora do acampamento. São relações de parentesco, de sanguinidade que se elaboram na dinâmica do processo de retomada numa experiência de memória de alianças não disciplinadas pelo cerco. O próprio autor, que além de antropólogo é advogado de defesa dos Guarani e Kaiowa, se vê como peça nessa teia de relações ao se dar conta que está servindo como meio de circulação de afetos ao transportar sementes enviadas por uma senhora da Reserva de Dourados (a quem Damiana se refere como "tia") para o acampamento Apyka'i. Operando como pontos de circulação de objetos e afetos os acampamentos reiteram redes de solidariedade e parentesco. Morais observa como a partir disso se constitui um sistema de trocas em que tudo que se recebe demanda uma volta: a semente será retribuída com um convite para uma celebração de colheita. Dessa maneira, o acampamento é o desafogo para o esparramamento represado na reserva. 
Diante do impasse dentro da etnologia se tais processos de reterritorialização são efeitos da política indigenista nacional ou se são realizações "próprias" de um ideário Guarani e Kaiowá, Morais aponta para a imagem do pêndulo em que a concepção de territorialidade vai de uma ponta a outra. Assim, o autor traz uma ideia de movimento muito cara aos Guarani e Kaiowá afirma ser este o próprio modo como os indígenas concebem o território, passando de uma chave para outra "sem muito constrangimento". Há de se destacar que, nos momentos de dilemas teóricos dentro da pesquisa, Morais sempre busca o discurso dos Guarani e Kaiowá como referência, evitando forçar encaixes em teorias ou mesmo alguma formulação nova. O etnógrafo busca incessantemente as categorias nativas e como essas estão operando na ação dos indígenas.

Acima de tudo, os acampamentos são a inversão da política da tutela. Eles reiteram relações indissociáveis da terra e que só podem ser vividas ali numa conexão direta entre solo e sangue. Damiana relata um sonho em que, abraçada ao próprio pai, se dá conta que ele é terra. Esse sonho é determinante para a cacique montar o acampamento de retomada e para Morais elaborar uma outra etapa do seu trabalho quando o corpo aparece como protagonista.

Composto por três partes - a alma, o "corpo substantivo" e angué, um espectro Morais apresentará o corpo como um ponto de articulação na cosmologia Guarani que tem sua gênese não numa substância mas numa relação. A alma é de natureza divina e após a morte deixará Terra, o "corpo substantivo" permanece e apodrecerá e angué é uma parte que permanece mas deve ser conduzida à sua morada à oeste, sentido oposto ao caminho da alma. Ao abordar a escatologia Guarani e Kaiowá, o trabalho mostra como o morto exige uma atenção constante dos vivos e especialmente o angué, que necessita tomar o seu caminho. Em vida, o corpo finca seu lugar na terra fazendo com que corpo e terra mesclemse reciprocamente, a morte não interrompe essa ligação: o angué mantém sua casa, seus itens e os visita com certa regularidade para conferir se tudo está organizado. Assim, uma série de ritos fúnebres devem dar rumo ao angué para que ele reconheça sua condição e não venha a dar cabo a jopara junto com os vivos. Quando desorientados seguem como corpos vazios - como os jovens na Reserva - assim cabe aos vivos auxiliarem na passagem de "morto" a "antepassado". O angué estabelece uma relação de dominância com seus objetos e com sua casa, voltando sempre esta para ver como está e por isso o cuidado dos vivos para com a casa do falecido é necessário para evitar desavenças. Dessa maneira, os cemitérios devem 
guardar uma distância adequada das casas, nem muito perto nem muito longe pois é preciso visitar as sepulturas constantemente para ajudar o angué a achar o seu caminho. Se a retomada organiza o espaço a partir do corpo em um terreno, a sepultura é uma casa a ser referência nas relações com o espaço e com o cosmos. Morais propõe a análise do corpo a partir da oposição entre o que é perecível e o que é imperecível, assim, a alma se estabelece no polo do imperecível e o "corpo substantivo" no polo do perecível. O angué, por sua vez, opera no polo da perecibilidade porém como imperecível. É aquilo que é eterno ou se renova infinitamente; é corpo mas imperecível aparecendo assim como centro das relações divinas e humanas.

A partir dessa figura do angué, Morais nota como o genocídio, o cerco e o desterro "desorganizam" a vida nas adjacências da morte: anguery não conseguem encontrar seus caminhos e povoam o mundo dos vivos desordenadamente, parentes procuram os corpos dos seus para poderem realizar enterros, um pedaço de fêmur é estendido por um jovem que questiona o antropólogo como será possível cuidar do osso de seu irmão se tiver que sair de sua terra. Em última instância a vida nessas circunstâncias gera dúvidas sobre quem (e o quê) está morto ou vivo. O angué desorientado sente raiva, uma fúria que levará os anguery a fazerem justiça contra os assassinados: "Vão mostrar para o homem branco que ele vai morrer também" (MORAIS, 2017:334).

Os acampamentos de retomada definem, então, uma ação política Guarani e Kaiowá que atravessa o corpo e dele deriva os seus sentidos para reorganizar o mundo. Do corpo à casa, do corpo à sepultura, do corpo à terra, o corpo é um ponto de referência na orientação da vida e da morte. Assim Morais aborda, por fim, a questão fundamental nessa reorganização do espaço pelo corpo: a capacidade de distinguir quem é vivo e quem é morto. Num cenário de extermínio, de desterro, de mortos sem corpo isso aparece como a possibilidade de que a própria vida no mundo siga existindo. "Enquanto houver deuses e homens, haverá angué; e quando não houver mais angué não haverá nada" (MORAIS, 2017:265). 